\title{
OPEN Variation of rhizosphere microbial community in continuous mono-maize seed production
}

\author{
Yunchen $\mathrm{Zhao}^{1,2 \bowtie}$, Wenjiang Fu ${ }^{1}$, Changwei Hu${ }^{2 凶}$, Guangquan Chen ${ }^{1}$, Zhanwen Xiao ${ }^{1}$, \\ Yuru Chen ${ }^{3}$, Zhijiang Wang ${ }^{1}$ \& Hongyu Cheng ${ }^{1}$
}

Soil microbe is crucial to a healthy soil, therefore its diversities and abundances under different conditions are still need fully understand.The aims of the study were to characterize the community structure and diversity of microbe in the rhizosphere soil after continuous maize seed production, and the relationship between the disease incidence of four diseases and the variation of the rhizosphere microbe. The results showed that different fungal and bacterial species were predominant in different cropping year, and long-term maize seed production had a huge impact on structure and diversity of soil microbial. Ascomycota and Mortierellomycota were the dominant fungal phyla and Mortierella and Ascomycetes represented for a large proportion of genus. A relative increase of Fusarium and Gibberella and a relative decrease of Mortierella, Chrysosporium, Podospora, and Chaetomium were observed with the increase of cropping year. Pathogenic Fusarium, Curvularia, Curvularia-lunata, Cladosporium, Gibberella-baccata, and Plectosphaerellaceae were over-presented and varied at different continuous cropping year, led to different maize disease incidence. Proteobacteria and Actinobacteria ranked in the top two of all bacterial phyla, and genus Pseudarthrobacter, Roseiflexus and RB41 dominated top 3. Haliangium and Streptomyces decreased with the continuous cropping year and mono-cropping of maize seed production increased disease incidence with the increase of cropping year, while the major disease was different. Continuous cropping of maize seed production induced the decrease of protective microbe and biocontrol genera, while pathogenic pathogen increased, and maize are in danger of pathogen invasion. Field management show great effects on soil microbial community.

Continuous mono maize seed cropping is very prevalent in Northwest of China for its high interest and unique geographical advantage, some fields even lasting more than 30 years, and resulted in serious obstacle of the crop $^{1}$. Maize crop is infected by approximately 65 pathogens including fungi, bacteria, and viruses ${ }^{2}$. In the continuous mono maize seed cropping system, the maize is generally suffered with high incidence of the disease like root rot, seedling blight, stem rot, and ear rot and as a consequence the yields decreased $6.75-9.36 \%{ }^{3}$. It's well known that those diseases are caused by numerous pathogens, such as Fusarium, Rhizoctonia solani and Pythium etc., resulted in large economic losses ${ }^{4}$, limiting quality improvement ${ }^{5}$, and restrained the development of industry chain and farmers' planting enthusiasm.

Soil microorganisms are key drivers of plant productivity in terrestrial ecosystem ${ }^{6}$. Studies showed that rhizosphere fungi play an essential role in plant growth and health of the plant-soil ecosystem ${ }^{7}$. Soil microbial community is thought to be responsible for biological processes that are necessary for maintaining a healthy soil and suppressing plant diseases ${ }^{8,9}$. Furthermore, it has been shown that a decrease in soil microbial diversity was responsible for the development of soil-borne plant disease ${ }^{10,11}$ which addressed that the differences in the rhizosphere microbial community may contribute to the differences in resistance to many disease. Generally, soil suppression relates to the biomass, activity and diversity of microbe at the community level and was reported to negatively correlate with invader survival ${ }^{12,13}$.

However, phyto-pathogenesis was complex, different plant species, location, and microbe community may lead to different disease incidence and resistance. Studies showed that pathogenic bacteria of maize rot of different part involved more than 30 species of Fusarium ${ }^{14}$, Penicillium, Aspergillus, and Rhizopus Nigricans etc.

\footnotetext{
${ }^{1}$ School of Agriculture and Ecological Engineering, Hexi University, Zhangye 734000, Gansu, China. ${ }^{2}$ College of Biological, Chemical Science and Engineering, Jiaxing University, Jiaxing 314000, Zhejiang, China. ${ }^{3}$ School of Food Science and Pharmaceutical Engineering, Nanjing Normal University, Nanjing 210000, Jiangsu, China. ${ }^{\square}$ email: yr1826@126.com; changwei.hu@163.com
} 


\begin{tabular}{|l|l|l|l|l|l|l|l|}
\hline Disease & A & B & C & D & E & F & G \\
\hline Seedling blight & $4.08 \pm 0.09 \mathrm{~d}$ & $3.29 \pm 0.26 \mathrm{e}$ & $7.83 \pm 0.93 \mathrm{a}$ & $8.23 \pm 0.65 \mathrm{a}$ & $5.18 \pm 0.53 \mathrm{c}$ & $6.25 \pm 0.57 \mathrm{~b}$ & $2.95 \pm 0.23 \mathrm{e}$ \\
\hline Root rot & $2.33 \pm 0.22 \mathrm{e}$ & $3.44 \pm 0.31 \mathrm{~d}$ & $4.57 \pm 0.35 \mathrm{~d}$ & $9.58 \pm 0.94 \mathrm{a}$ & $8.15 \pm 0.72 \mathrm{~b}$ & $8.21 \pm 0.68 \mathrm{~b}$ & $7.23 \pm 0.14 \mathrm{c}$ \\
\hline Stem rot & $6.82 \pm 0.55 \mathrm{~d}$ & $10.11 \pm 0.08 \mathrm{~b}$ & $8.68 \pm 0.67 \mathrm{c}$ & $13.55 \pm 0.14 \mathrm{a}$ & $12.03 \pm 0.09 \mathrm{a}$ & $10.11 \pm 0.11 \mathrm{~b}$ & $9.25 \pm 0.07 \mathrm{bc}$ \\
\hline Ear rot & $3.33 \pm 0.43 \mathrm{~d}$ & $4.18 \pm 0.46 \mathrm{~d}$ & $5.22 \pm 0.38 \mathrm{c}$ & $7.24 \pm 1.1 \mathrm{~b}$ & $8.64 \pm 0.71 \mathrm{~b}$ & $12.92 \pm 1.1 \mathrm{a}$ & $12.02 \pm 0.28 \mathrm{a}$ \\
\hline
\end{tabular}

Table 1. The disease incidence (\%) of different continuous cropping year. All the number were expressed with standard error, lowercase letter in the same line means significant difference at $p<0.05$.

\begin{tabular}{|l|l|l|l|l|l|l|l|}
\hline Disease severity & A & B & C & D & E & F & G \\
\hline Seedling blight & 2 & 2 & 2 & 2 & 2 & 2 & 1 \\
\hline Root rot & 1 & 1 & 1 & 2 & 1 & 2 & 1 \\
\hline Stem rot & 2 & 1 & 2 & 2 & 1 & 2 & 1 \\
\hline Ear rot & 2 & 1 & 2 & 2 & 2 & 2 & 2 \\
\hline
\end{tabular}

Table 2. The severity of different disease in different continuous cropping year. 1 means level one, 2 means level two, 0 means no disease incidence.

Fusarium and Aspergillus infection caused root rot at first, then stem rot, then ear rot at the next coming years under some location and conditions ${ }^{15}$. To date, the effective methods to effectively control those diseases are still scarce. In addition, there is lack of knowledge on microbial community structure and diversity of rhzisophere of continuous maize seed production. Hence, analysis of the community composition and structure of rhizosphere microbe of maize seed continuous cropping fields, and identify the predominant pathogens causing maize disease of high incidence during a season are helpful to prevent those disease. Therefore, considerable interest should be paid on monitoring the composition and variation of soil microbial communities in different continuous mono cropping year of maize seed production.

In present study, variation of rhizosphere microbial community in different continuous cropping year of maize seed production was investigated to characterize fungal and bacterial communities in the rhizosphere soils. We aimed to (1) evaluate the impact of mono-cropping on diversity and structure of soil microbial communities in the continuous maize seed production, (2) determine the dynamic change of pathogenic bacteria of different cropping year, (3) estimate whether the continuous mono-maize seed production causing serious pathogenic bacteria accumulation in different mono-cropping year, and (4) reveal the relationship between root rot, stem rot, seedling blight, ear rot and the dynamic change of microbe community of maize seed production system.

\section{Results}

The disease incidence during growth stage and the severity. Generally, the disease incidence increased with the increase of continuous cropping year with exception of 30 years with stubble (Table 1). The highest disease incidence of seedling blight and ear rot was $8.23 \%$ of 20 years continuous cropping and $12.92 \%$ of 30 years continuous cropping without field maize, respectively. The ear rot incidence of continuous cropping for 5 years was lower than the others, and no difference was observed between 5 and 10 years cropping. The highest disease incidence of root rot and stem rot was 20 year continuous cropping of $9.58 \%$ and $13.55 \%$, respectively. Obviously, continuous mono-cropping of maize seed production could increase disease incidence with the increase of cropping year, while the incidence of four diseases differed among different continuous cropping year (Table 1).

Most of the disease severity of different plots of different cropping year was characterized of level 1 or 2 . It can be seen that the disease severity of seedling blight, stem rot and ear rot, which was the common disease in the area of maize seed production, were high in most cropping years. The disease severity of ear rot increased with the cropping year, while the disease severity decreased at 30 years with field maize of seedling blight and root rot. The disease severity of root rot was relative slight than that of others disease in almost all different cropping years (Table 2).

The community diversity of fungi after mono maize seed cropping. After sequencing DNA isolated from the samples by using high-throughput DNA sequencing, 118, 000 optimized sequences with average lengths of 200-260 bp were retained through filtered from 120,000 valid ITS sequences. The Chao 1, the observed-species, the PD-whole-tree, and Shannon index of the samples were chosen to represent the real diversity of the microbes in the samples (Fig. 1).

The Chao1, PD-whole tree, Shannon index was indices at 97\% similarity. The highest and the lowest Shannon index, observed-species, Chao1 were observed in 30 years and 10 years cropping soil, respectively (Fig. 1). The number of OTUs observed increased with the number of sequence sampled, and reached the near plateau region at $97 \%$ similarity level. The rarefaction curves trended to be increased continuously as the number of sequences increased (Fig. 2A), and with exception of 172 common OTUs, the upper limit of OTUs for 5, 10, 15, 20, 25, 
chao1

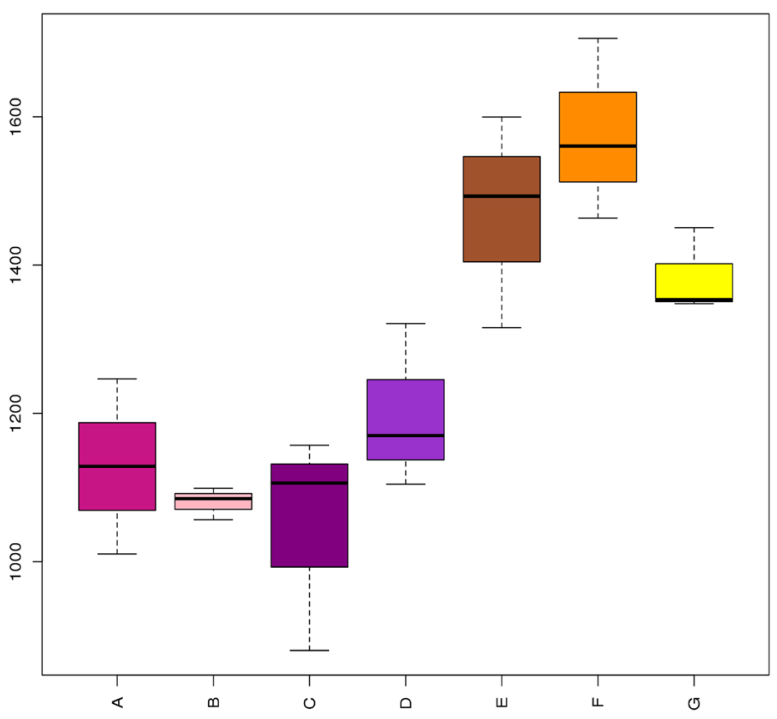

PD_whole_tree

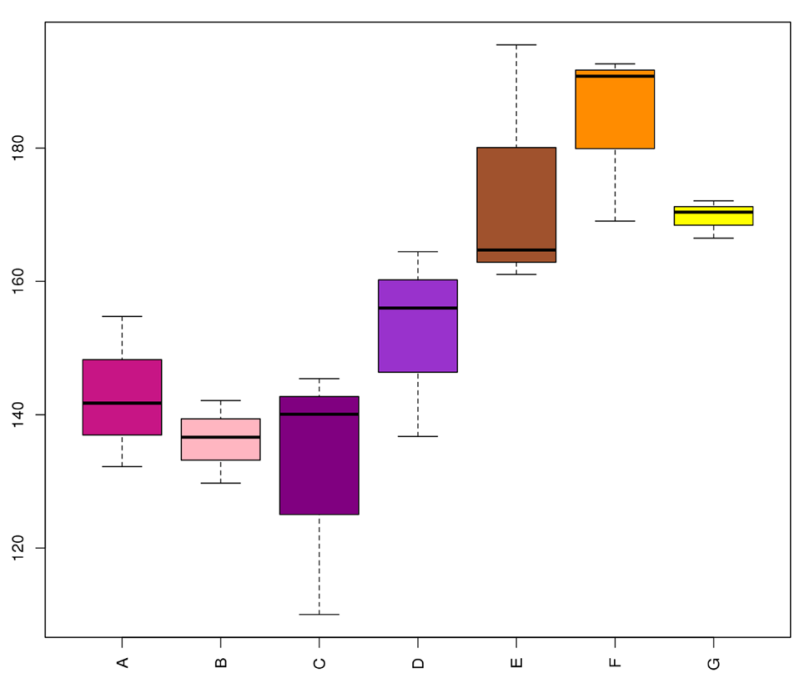

observed_species

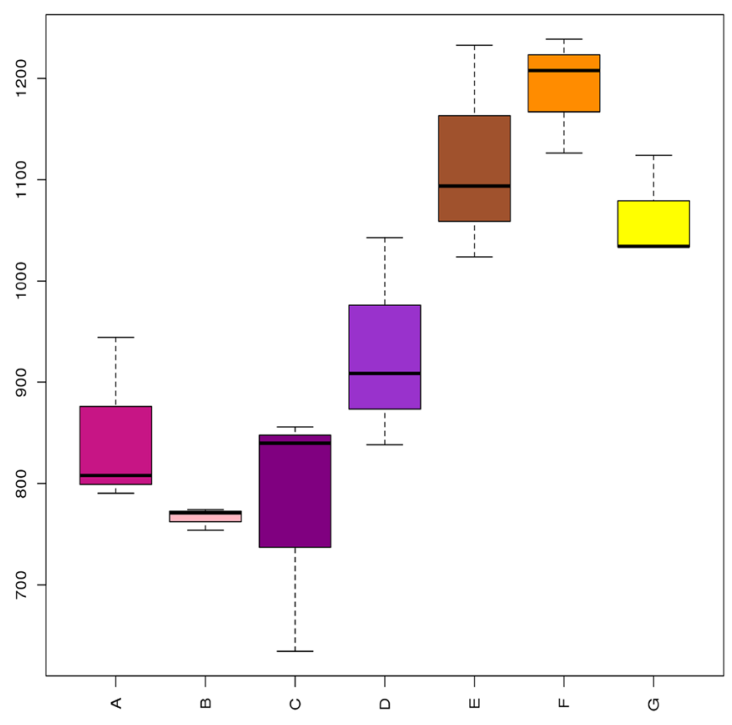

shannon

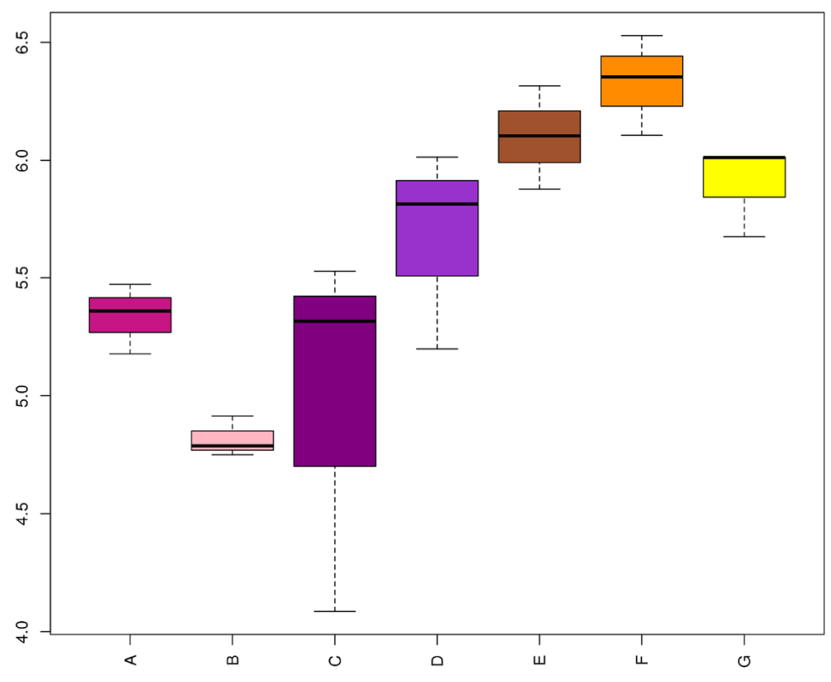

Figure 1. Chao1, observed-species, $\mathrm{PD} \_$whole_tree, and Shannon index of fungi of different continuous cropping year. Uppercase of A, B, C, D, E, F and G represent 5,10,15, 20, 25, 30 years, and 30 years with stubble cropping, respectively.

and 30 cropping year were 703, 619, 630, 785, 976, 1056 and 922, respectively (Fig. 2B). The rank-abundance curves are all decreased and flatted at the end, and ranged higher than 10 yeas on the $\mathrm{x}$-axis, showing a higher abundance in 30 and 25 years, with the highest for 30 years (Fig. 2C). Continuous cropping enriched the fungal community diversity and richness, and the diversity increased over continuous cropping years with exception of 10 years cropping.

The relative abundance of fungi community. The diversity and relative abundance of the rhizosphere fungal community was significantly different with different continuous cropping year. At phylum level, most fungal sequences were dominated distributed at Ascomycota, Mortierellomycota, Basidiomycota, Glomeromycota, and Rozellomycota. Especially, Ascomycota was the most dominant fungal phylum and represented $65.98 \%$ on an average of all fungal DNA sequence. Five known fungal phyla accounted for $76.09-89.01 \%$ on an average of all. There still presented $12.45-23.91 \%$ unidentified and others fungal phyla of all, and unidentified phylum increased with the increase of continuous cropping year (Fig. 3A). At the genus level, the abundance of the sorting results, ordered from high to low, were Mortierella, Chrysosporium, Pseudeurotium, Fusarium, Podospora, Chaetomium, Exophiala, Bipolaris, Gibberella, Acremonium, Clasosporium, Microascus, Cladorrhinum, Guehomyces, Scopulariopsis, Plectosphaerella, Wardomyces, Tetracladium, Inocybe, Holtermanniella, and Bionectria that belongs to different phylum. Considerable fungi genus at rhizosphere soil were unclassified and showed a relative increase in 20 years cropping. A certain proportion of potential pathogenic pathogen of Fusarium, Gib- 
A

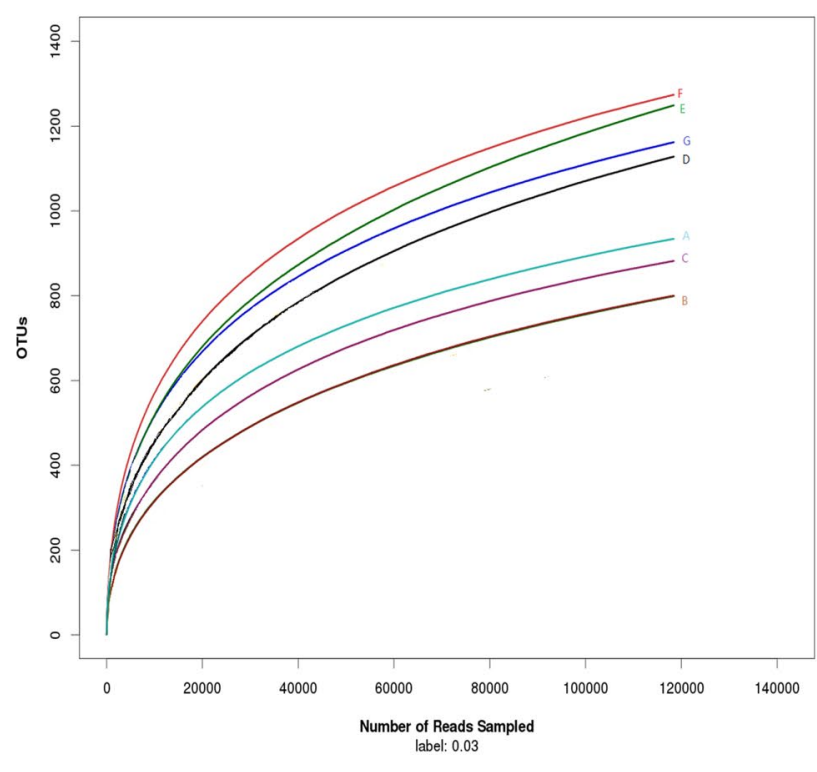

B

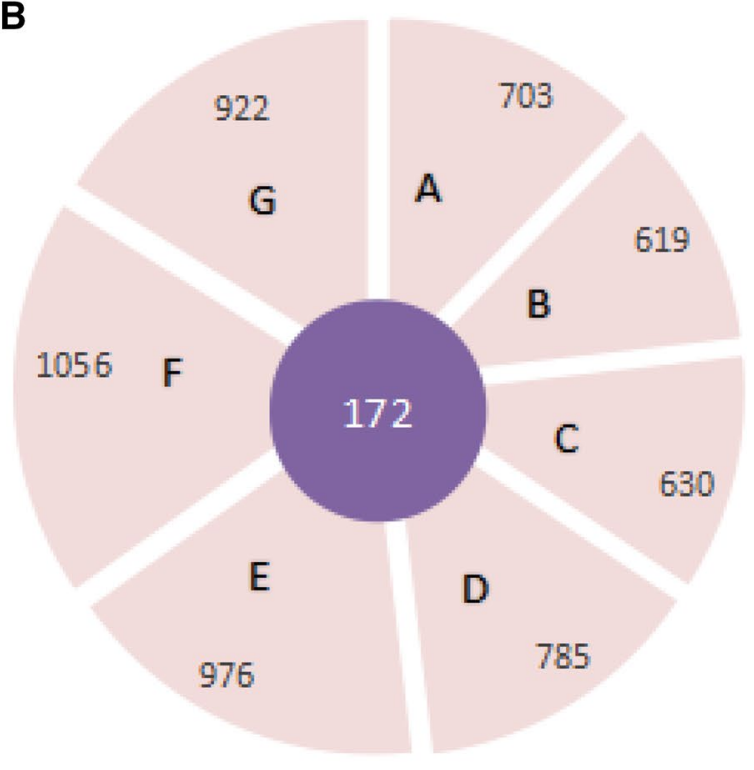

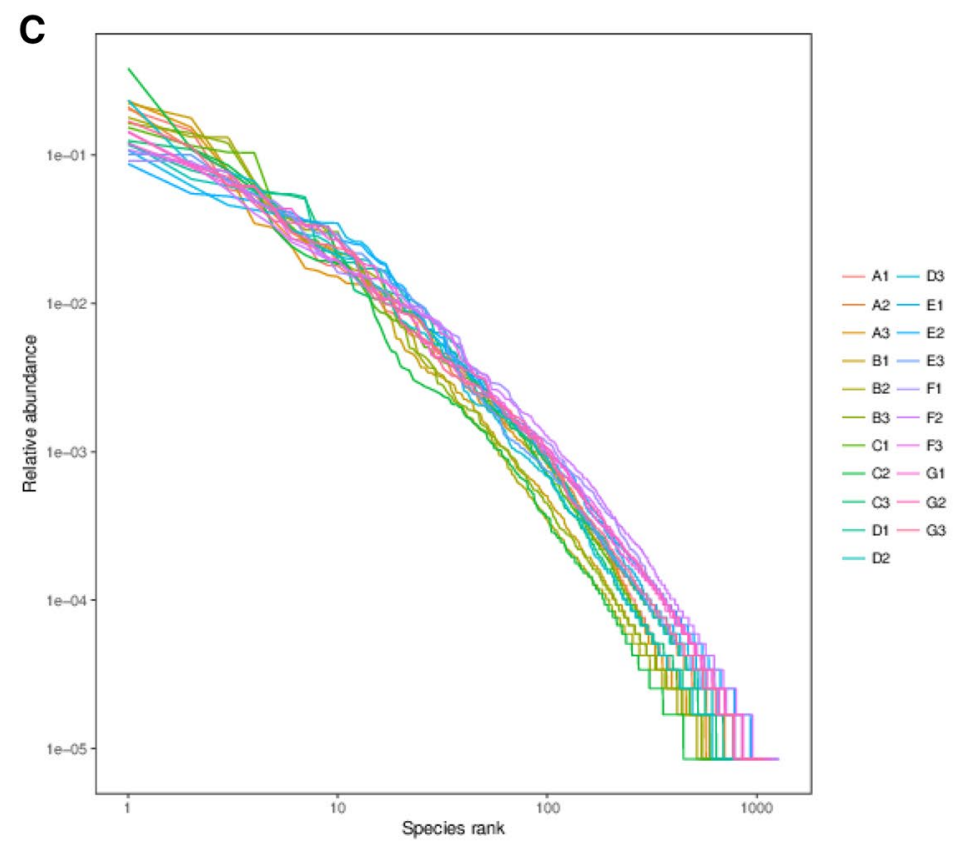

Figure 2. (A) Rarefaction curves of OTUs clustered at $<97 \%$ sequence identity for 21 different rhizoshpere soil samples of corn seed production from $5,10,15,20,25,30$ and 30 years of continuous cropping. Uppercase of A, B, C, D, E, F and G represent 5, 10, 15, 20, 25, 30, and 30 years, respectively. The subscript below the letter represent three duplicates of the same cropping year. The OTUs reads of different samples are shown in different colors. (B) Flower graph of OTUs of different continuous cropping year. Uppercase A, B, C, D, E, F, and G represent $5,10,15,20,25,30,30$ years, respectively. The core was the common OTUs for different treatment. (C) OTUs relative abundance curves for the OTUs in the 21 different corn seed production rhizoshpere soil samples from $5,10,15,20,25,30$ and 30 (with field corn) years of continuous cropping. Uppercase A, B, C, D, E, F, and G represent $5,10,15,20,25,30$, and 30 years, respectively. The subscript below the letter represent three duplicates of the same cropping year. The OTUs reads of different samples are shown in different colors.

berella, Cladosporium, Acremonium, and Bipolaris was detected in the rhizosphere soil of different continuous cropping year. It is worthy note that the relative abundance of Fusarium, Gibberella, Cladosporium, Exophiala and the relative depletion of Mortierella, Podospora, Chrysosporium and Chaetomium at different continuous cropping year (Fig. 3B). According to Lefse analysis, speicies Gibberella-Baccata was enriched in the rizosphere soil of 30 years cropping with 3 years field maize planting history. The key genus as Fusarium, Curvularia, Currlaria-lunata were dominated in 30 years continuous cropping, and genus Chaetochyriales was dominated in 25 years. Species Mortierella-Elongata in the soil of 20 years cropping, and genus plectosphaerellaceae in the soil 
A

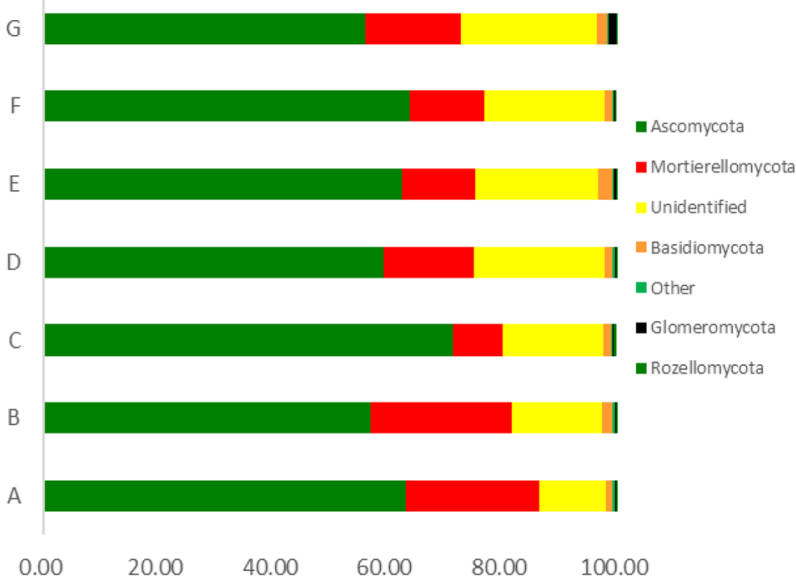

B

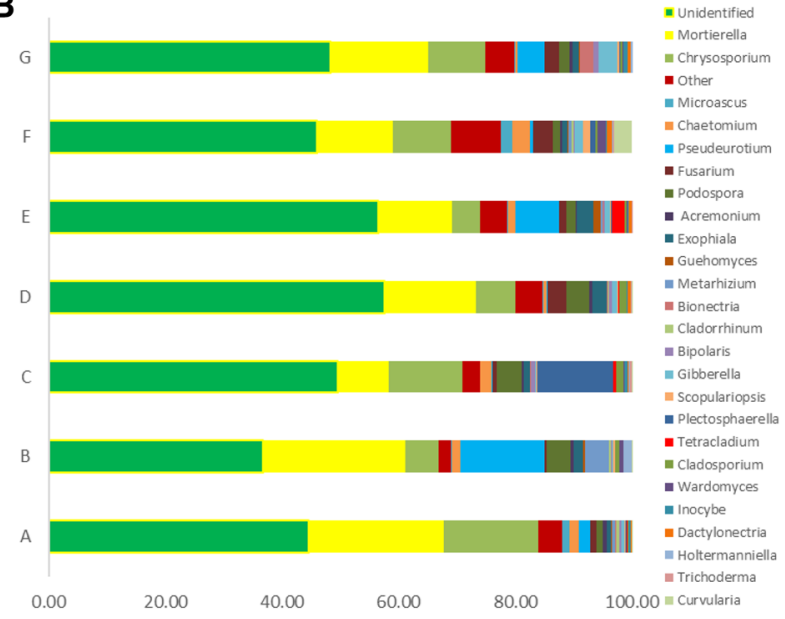

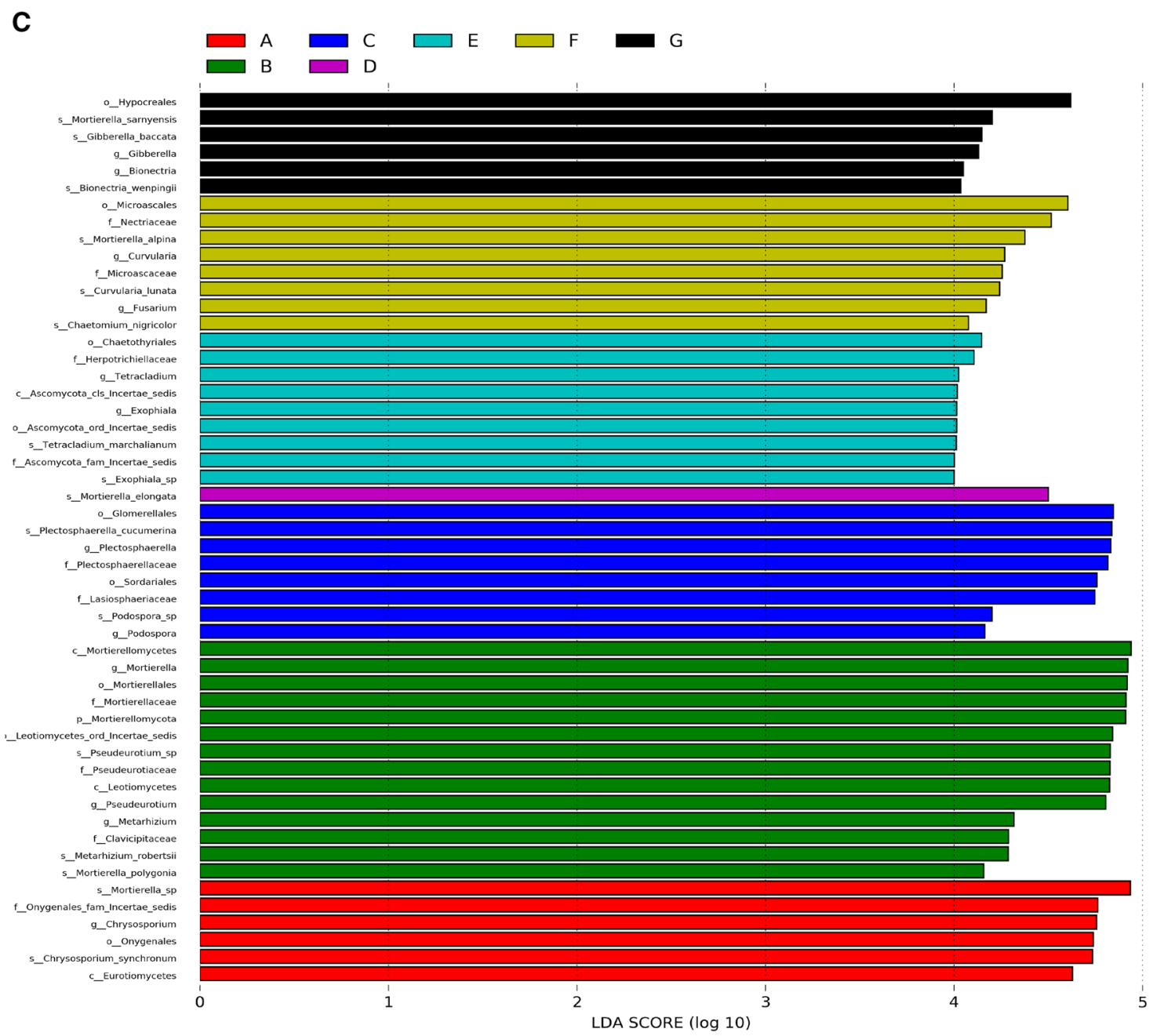

Figure 3. (A) Composition of the different fungal communities at the phylum level in seven rhizosphere soil samples. The relative abundance of different fungal phylum within the different communities are shown in different colors. Unidentified means there was no taxonomic information, and Other means many function group. (B) Composition of the different fungal communities at the genus level in seven rhizosphere soil samples. The relative abundance of different fungal genus within the different communities are shown in different colors. Unidentified means there was no taxonomic information, and Other means many function group. (C) LDA score of the fungi of different cropping year. The figure shows species whose LDA Score is greater than the set value (LDA score $>2$, less-strict set to 2; More-strict was set as 4), that is, biomarkers with statistical differences between groups. The length of the bar chart represents the significance of the different species. 

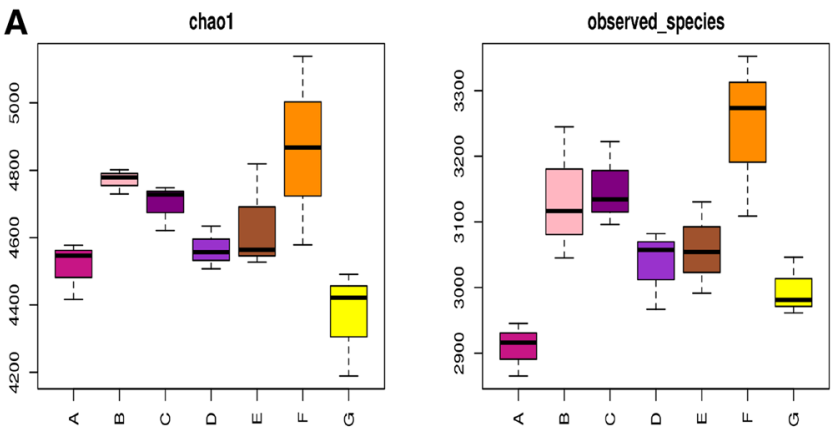

B
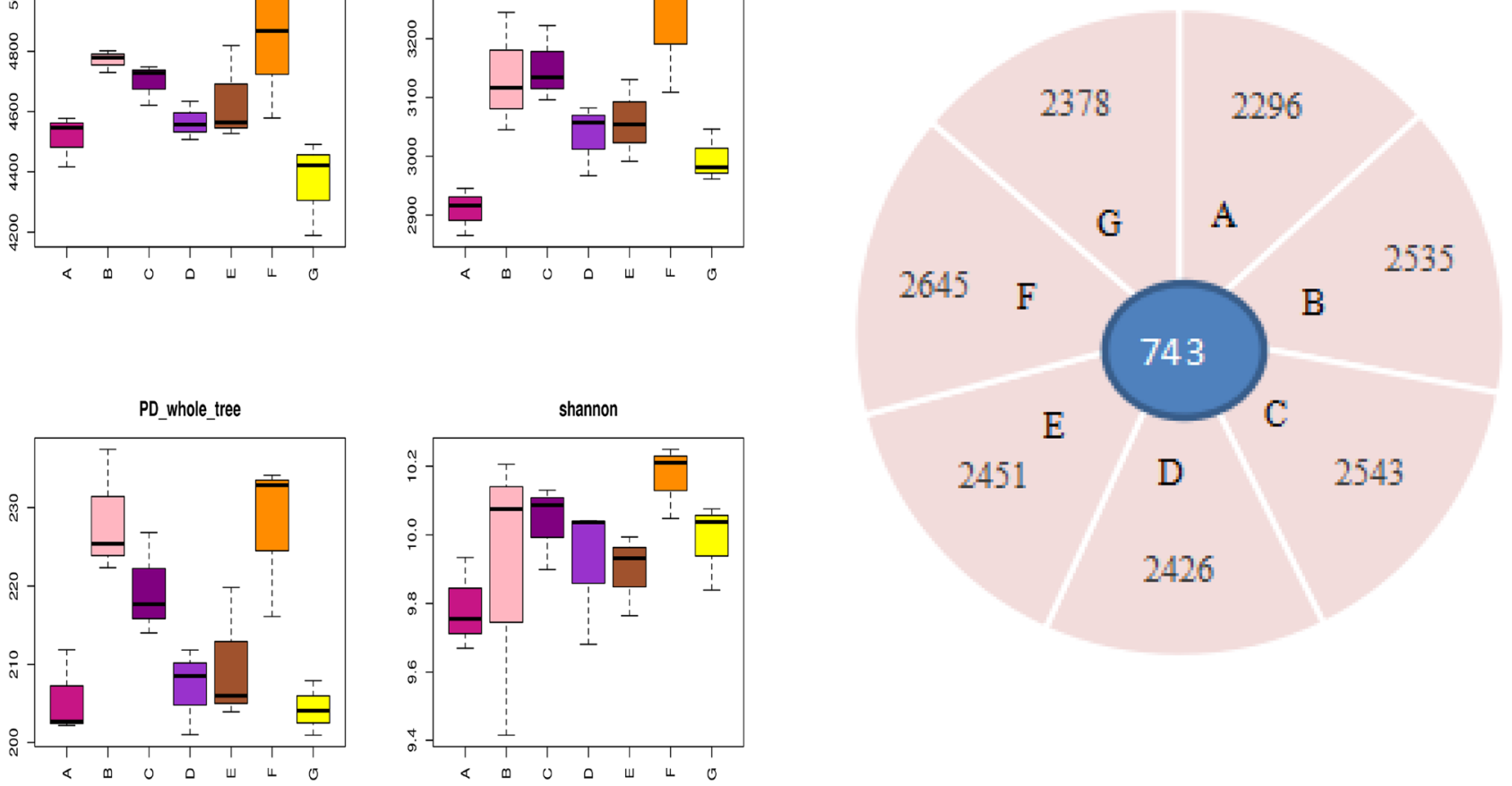

Figure 4. (A) Chao1, observed-species, $\mathrm{PD}$ _ whole _tree, and Shannon index of bacteria of different continuous cropping year. Uppercase of A, B, C, D, E, F, and G represent 5, 10, 15, 20, 25, 30, and 30 years cropping, respectively. (B) Venn diagram of the bacteria of different continuous cropping year. A, B, C, D, E, F, and $\mathrm{G}$ represents 5, 10, 15, 20, 25, 30, and 30 years cropping, respectively.

A

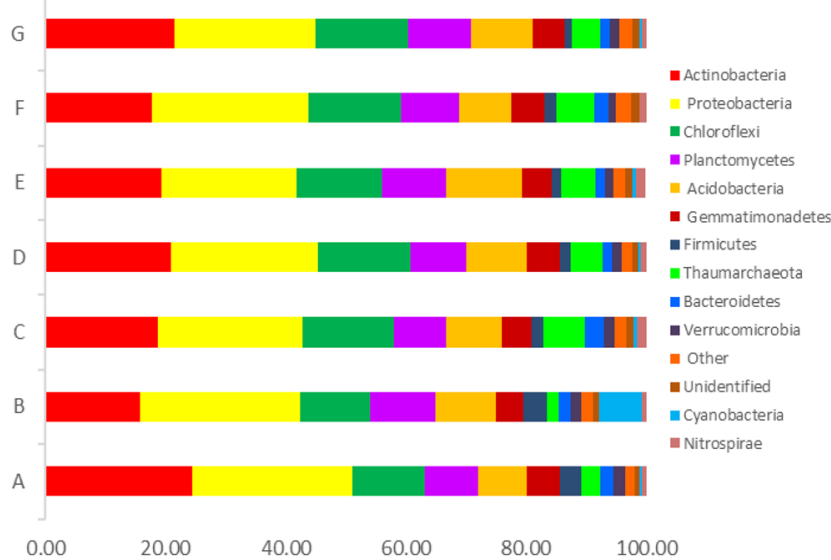

B

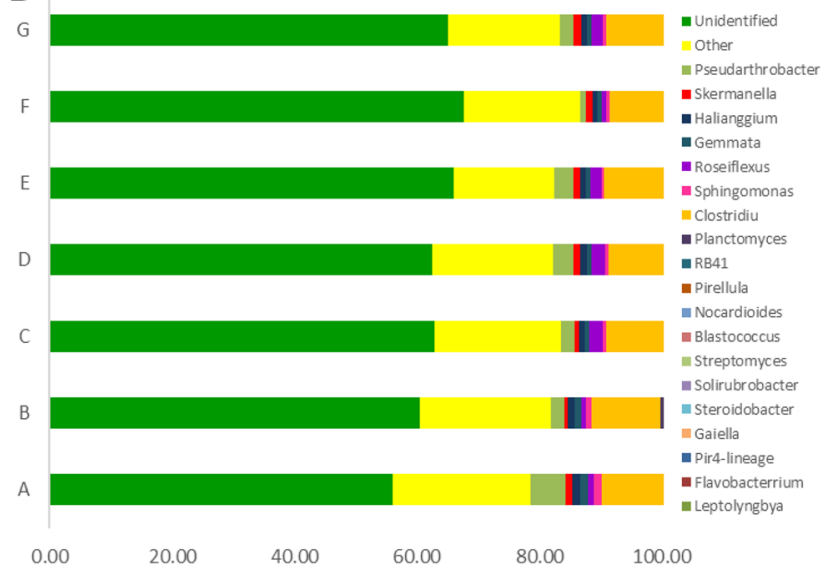

Figure 5. (A) Bacterial Phylum of different cropping years based on mean read numbers per sample. (B) Bacterial genus of different cropping years based on mean read numbers per sample. (C) LDA score of the bacteria of different cropping year. The figure shows species whose LDA Score is greater than the set value ( LDA score $>2$, less-strict set to 2; More-strict was set as 4), that is, biomarkers with statistical differences between groups. The length of the bar chart represents the significance of the different species. 
C
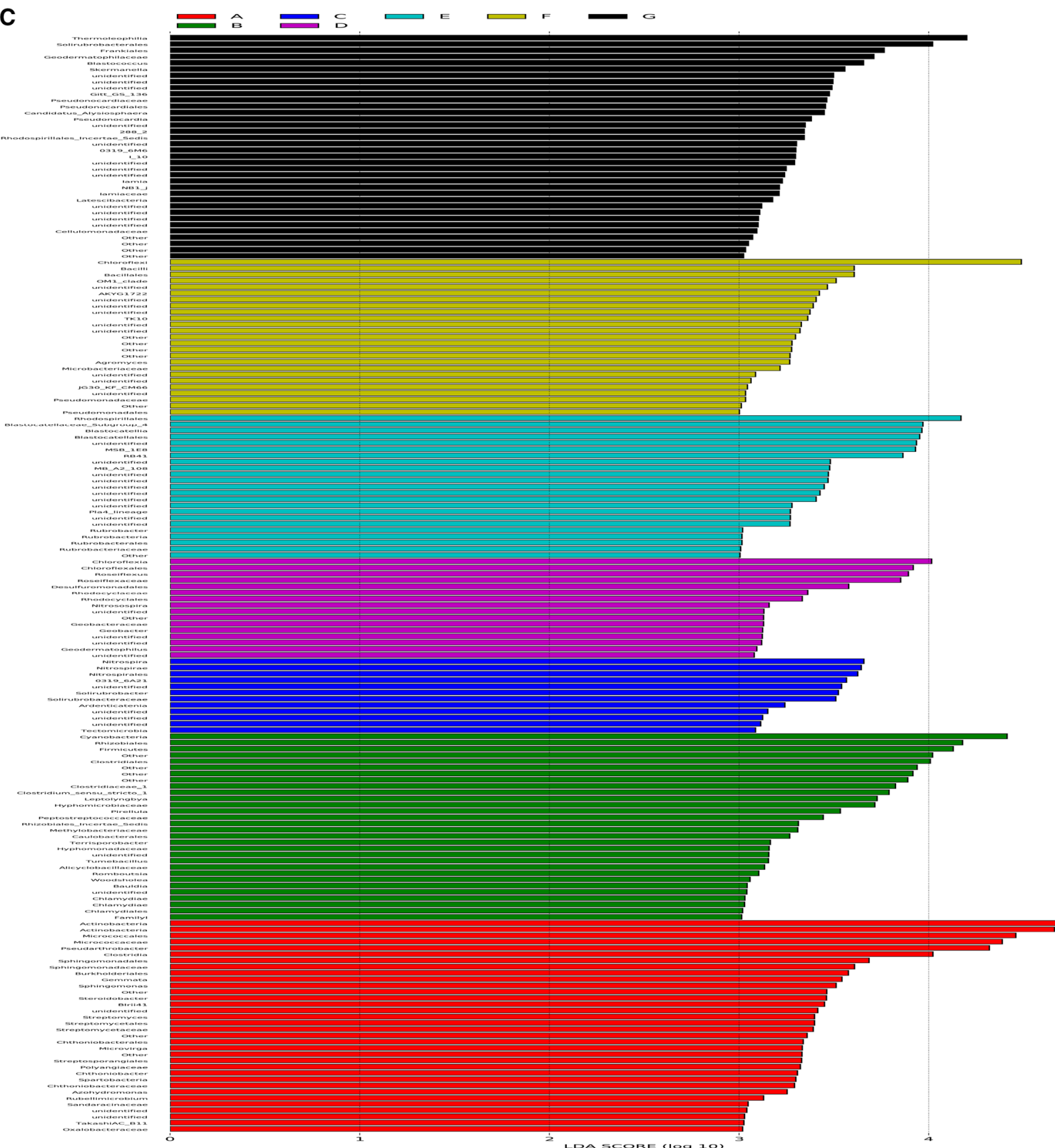

Figure 5. (continued)

of 15 years continuous cropping were more enriched than the other treatments. Class Mortierellamycetes and species Mortierella_sp were over-represented in the rhizosphere soil of 10 and 5 years continuous cropping year, and these key phyla potentially contributed to the structural segregation of different years (Fig. 3C).

The community diversity of bacteria after mono continuous cropping. The results reflected significant differences among the samples in bacteria community composition $(P<0.05)$, and a higher Chaoland Shannon index over 30 years and 10 years cropping with the highest for 30 years cropping without field maize were observed. Twenty-five years cropping showed the highest, while 5 years cropping showed the low- 
est observed-species and PD tree (Fig. 4A). Eighteen thousand optimized sequences with average lengths of 200-260 bp were retained through filtered from 21, 000 valid sequences. The rarefaction curves trended to be decreased as the number of sequences increased, and the upper limit of OTUs 0.03 were 2735, 2952, 2415, 2655, 2679,3220 and 2805 respectively. The Venn diagram showed that there were 743 common OTUs among the continuously cropped soil samples and 2296, 2535,2543, 2426, 2451, 2645 and 2378 else OTUs were found in 5, $10,15,20,25,30$, and 30 years continuous cropping (Fig. 4B). As revealed by high throughput sequencing that continuous cropping induced different number of OTUs and the bacterial diversity and structure of community varied among different continuous cropping years.

The relative abundance of bacteria of rhizosphere soil. The relative abundance of the assigned bacteria phyla and genera was compared among the different samples (Fig. 5). The results showed that Proteobacteria, Actinobacteria, Chloroflexi, Planctomycetes, and Acidobacteria were located in the top five among all bacteria phyla, which counted $22.46-26.71 \%, 15.70-24.43 \%, 11.6-15.45 \%, 8.65-10.91 \%$, and $8.07-10.38 \%$ of different cropping year, respectively. Proteobacteria was enriched in rhizosphere soils of 10 years cropping, whereas, Gemmatimonadetes and Thaumarchaeota were depleted at 10 years cropping. Proteobacteria is a key phylum in the rhizosphere soil of continuous maize seed production (Fig. 5A). Two genera of Flavobacterrium and Leptolyngbya exhibited lower abundance, while Pseudarthrobacter, RB41, and Roseiflexus exhibited higher abundance in different soil samples, and the relative abundance of which accounted for $0.02-0.72 \%, 0-1.32 \%$, $0.97-5.75 \%, 0.77-2.43 \%$, and $0.71-2.23 \%$, respectively. Haliangium and Streptomyces were also presented in the soils, which occupied $0.84-1.4 \%$ and $0.38-0.86 \%$ in different cropping year (Fig. 5B). Long-term mono maize seed cropping enriched the amount of Roseiflexus and Blastococcus in maize rhizosphere soil. Continuous cropping induced large changes in the bacterial flora in maize rhizosphere soil. According to analysis of Lefse, Actinobacteria and Cyanobacteria were dominated at 5-10 years cropping, while, Chloroflexi and Roseiflexus were over-presented at 20 years cropping. Blastocatellaceae-subgroup-4 and Rhodocyclaceae was dominant at 25 years cropping, Thermoleophilia and Solirubrobacterales were dominated at 30 years cropping with field maize, while Chloroflexi and Bacilli was dominated at 30 years cropping without field maize (Fig. 5C).To gain deeper insight into the differences between the groups, a profile clustering network analysis was applied. The profile obtained by a Cytoscape network analysis showed all the phyla and highlighted the distribution and relative abundances of all phyla of different cropping years(Fig. 6A,B). Five years cropping enriched Actinobacteria, 10 years cropping has relative abundance of Firmicutes, 15 years cropping highlighted Nitrospirae and Tectomicrobia, and 30 years cropping highlighted Chloroflexi. From family level, 10 years cropping enriched Geodermatophilaceae and OM1_clade, 15 years cropping enriched Blastocatellia and OM1_clade. Thirty years cropping with field maize enriched Blastocatellaceae_sugbgoup_4, Geodermatophilaceae, Blastocatellia, OM1_clade, Geodermatophilaceae, Frankiales, Pseudonocardiaceae and Cellulomatophilaceae, while 30 years cropping without field maize enriched Blastocatellia, OM1_clade, Frankiales and Lamiaceae. Significant difference of relative abundance on different cropping year of different phyla and genera were clearly observed $(P<0.01)$. OTU_20 of Proteobacteria was more correlated to OTU_6 of Chloroflexi, and OTU_2 of Thaumarchaeota was more correlated to OTU-45 of Actinobacteria. Co-occurrence of different phyla was clearly showed as well (Fig. 6A,B).

Relationship between disease incidence and microbial community composition. From the results of RDA of fungi, root rot, seedling blight, and ear rot showed the similarly variation trends, and their disease incidence was significant positively related with Podospora, Trichoderma, Tetracladium and Exophiala. While, above mentioned diseases were significant negatively related to Microascus, Cladosporium, Acremonium, Chaetomium, and Pseudeurotium. Stem rot was significant positively related to Fusarium, Gibberella, Bipolaris, Plectosphaerella, while the disease incidence of it was significant negatively correlated to Wardomyces, Chrysosporium, Curvularia and Holtermanniella. Different pathogenic pathogen led to different disease incidence in different continuous cropping year (Fig. 7A).

From the results of RDA of bacteria, the disease incidence of continuous cropping of 5 years was significant positively correlated to Pseudarthrobacter, Gemmata, Steroidobacter, Pirellula, Sphingomonas, Halianggium, Nocardioides, Clostridiu, Pir4-lineage, Pirellula, Streptomyces, and 10 years cropping was positively related to all above mentioned bacteria. Continuous cropping of 15 years was significant positively related to Flavobacterrium and Leptolyngbya, and 20 years cropping was positive related to Pseudarthrobacte. Cropping 30 years was positively related Planctomyces, Flavobacterrium, and genus Unidentified, and cropping 30 years was significant positively related with them. Continuous cropping of 25 years and 30 years with field maize was significant positively related to genera Roseiflexus, Blastococcus, Solirubrobacter, RB41, and Skermanella (Fig. 7B).

\section{Discussion}

Study results showed that soil microbial communities are influenced by multiple factors such as plant type, soil properties $^{16}$, and fertilization ${ }^{17}$. Long-term fertilization is correlated with differences in both composition and community-level physiological profile of soil microbial communities ${ }^{18}$. Inappropriate fertilization can reduce bacterial diversity ${ }^{19}$. Present study is a long-term chemical fertilization system and located in an arid and semiarid region. Ascomycota, Basidiomycota and Mortierellomycota were dominant phyla after long-term continuous cropping of maize seed production, which was consistent with the results of previous study ${ }^{7}$. Ascomycota tended to reside in cooler and arid area because of their evolutionary histories ${ }^{20}$, and its many species play a major ecological role as decomposers ${ }^{21}$. Our research was also consistent with Lauber et $\mathrm{al}^{22}$, who set forth that higher Ascomycota than Basidiomycota in P-rich soils $(8.96-12.51 \mathrm{mg} / \mathrm{kg})$. At the genus level of fungi, Mortierella and Chrysosporium dominated in rhizosphere soil, Fusarium, Giberrella, and Pseudeurotium were 
the important microbe for community composition. The most abundant genera in our study play important roles in different continuous cropping year because the highest abundance of sequences belonged to different species. The abundance of most dominated Mortierellales decreased with continuous cropping year indicating a decrease of protective microbe ${ }^{7}$. Proteobacteria comprised of $22.46-26.71 \%$ of all bacterial communities in different continuous cropping year, confirming that it is still an important soil bacterial group after 30 years monoculture. Specific taxa of Actinobacteria, Acidobacteria, and Proteobacteria showed significant shifts across the increased cropping year. The relative abundance of Proteobacteria and Actinobacteria decreased, while that of Acidobacteria increased with the continuous cropping, which was consistent with Lauber et al. ${ }^{23}$, who pointed out that Proteobacteria, Actinobacteria and Acidobacteria were the top three phyla in the soil. At the genus level, as many of the less abundant groups of Actinobacteria showed a propensity for soil environment with reduced carbon or nutrient availability. Chloroflexi occupied a certain property in our studied area, though it is un-culturable ${ }^{23}$. Results showed that Proteobacteria and Actinobacteria were greatly responsive to soil $\mathrm{pH}$ and $\mathrm{SOC}^{24}$ and the decrease of Proteobacteria and Actinobacteria may be caused by the decrease of soil organic matter and $\mathrm{pH}$ value ${ }^{1}$. Difference of microbial community may be caused by the difference of the physicochemical properties, such as soil type or $\mathrm{pH}$ under the same management ${ }^{25,26}$ and land use type $\mathrm{e}^{24}$. The possible explanation for the different variation of microbial community of field $G$ with the other fields might related to the effects of its field management which was mostly coherent with its edaphic matrix. Seed maize's pollination, production model, parents, yields and residues treatment are greatly differed with that of field maize. Field maize has higher yield, loosely pollination, stubble returning, and lower dose fertilization. Influence on the field G from the field management were obviously visible from planting history.

Intensive research attempts are underway to improve plant growth and tolerance to various abiotic stresses, and to protect plants from soil borne pathogens using plant growth promoting bacteria ${ }^{27-30}$. While, optimum environment conditions are needed for growth of some fungal colonies, because they failed to synthesize some key compounds by lacking of some key conditions, and fungi are widely different on obtaining nutrients from the medium of basal. Some biocontrol genera presented in rhizosphere soil of maize such as Halianggium and Streptomyces, while the abundance of the genus decreased with the increase of continuous cropping year. Haliangium can produce haliangicin that can inhibit the growth of a wide spectrum of fungi ${ }^{31}$. Streptomyces usually inhabit soil and can produce tubercidin and phosphlactomycin that was effective to biological control ${ }^{32}$. Podospora and Chaetomium can potentially decrease the population of harmful fungi and act as biological control to pathogen in the field, and Cladorrhinum has the beneficial effect on increasing absorption of phosphorus in the field. Similarly, rhizosphere Pseudomonad produced antibiotics, and rhizosphere Bacilli produced lipopeptides and polyketides, biosurfactants, and volatile organic chemicals ${ }^{33-36}$. It is worthy that the relative decrease of benificial microbe of Podospora, Chaetomium, and Cladorrhinum will potentially lead to decrease of beneficial secretions around rhizosphere. Our results confirmed that long term mono cropping of maize seed production caused a decrease of biocontrol genera and a decline of plant beneficial microbe in the rhizosphere soil.

Rhizosphere fungal communities are considered critically important for plant health and soil fertility. Generally, continuous cropping practices and severe root-rot disease affected the community structure and diversity of rhizosphere and root endophytic fungi ${ }^{37}$. Root associated microbes, including endophytes, closely cooperated with each other and can mediate important physiological processes, especially nutrient acquisition and plant fitness to abiotic stresses ${ }^{38,39}$. In the present study, most of those relative increased genera as Fusarium, Gibberella, Bipolaris, Acremonium, Plectosphaerellaceae, Curvularia, and Cladosporium are potential phytopathogens caused maize disease such as root rot, stem root, and ear rot in continuous cropping. With seriously harm to the agroecosystem, the eradication of above mentioned pathogens is difficult with the pathogens accumulating in cultivated soils and then significantly impact maize seed production. Fusarium was considered the major pathogen of root $\operatorname{rot}^{40}$, and Gibberella was considered the major pathogen of ear rot. F. oxysporum $\mathrm{f}$. sp. Niveum (FON) is considered to be the most important soil-borne facultative pathogen, causing economically important losses and limiting production in many areas of the world ${ }^{11}$. Genus Bipolaris includes important plant pathogens with worldwide distribution ${ }^{41}$, and Curvularia leaf spot, caused by Curvularia lunata (Wakker) significantly reduces the yields of maize ${ }^{42}$. As evidence from the disease incidence of 4 different disease, the increase of Fusarium, Gibberella, Bipolaris, cladosporium, and Acremonium increased relative abundance of potential pathogen in different cropping year, and the decreased diversity of Podospora, Chaetomium, and Cladorrhinum suggesting that the plant protection decreased and the maize is in danger of pathogen invasion. More attention should be devoted to make clear the variation of those microbial communities such as Fusarium, Gibberella and Bipolaris etc. Study results showed that an optimum microbial community can promote soil defense capability ${ }^{43}$. It has been demonstrated that some root associated microbes may reduce the peroxidation of membrane lipids, thereby strengthening the ability of membranes to withstand abiotic stress ${ }^{39,44}$.

Disease severity is the intensity of disease prevalence based on specific scale of rating as described in the results of Lambert and Whites ${ }^{45}$. The spores of the pathogen can survive in the soil for several years which increased the difficult to disease control or prevention. Once the pathogen is established in soil, the soil will be unsustainable to maintain the plant production. In the present study, different continuous cropping fields under the same management, same climate conditions and similar soil properties indicated different disease incidence and severity led to different variation of soil microbial community. In many instances, these diseases are caused by a complex of fungal species ${ }^{7}$. In the same way, pathogenic pathogen caused four diseases in the study are a complex of fungal species, therefore, different pathogenic pathogen dominated at different cropping year led to different disease and disease incidence. Furthermore,variations in rhizosphere microbial community structure may also make the root more susceptible to pathogen infection and appeared different disease incidence. In the studied area, disease severity increased of maize root-rot and stem-rot in July and August, as environmental and weather conditions are optimal for the pathogens invasion. Novel and adaptive methods should be developed to 
A

Cladogram

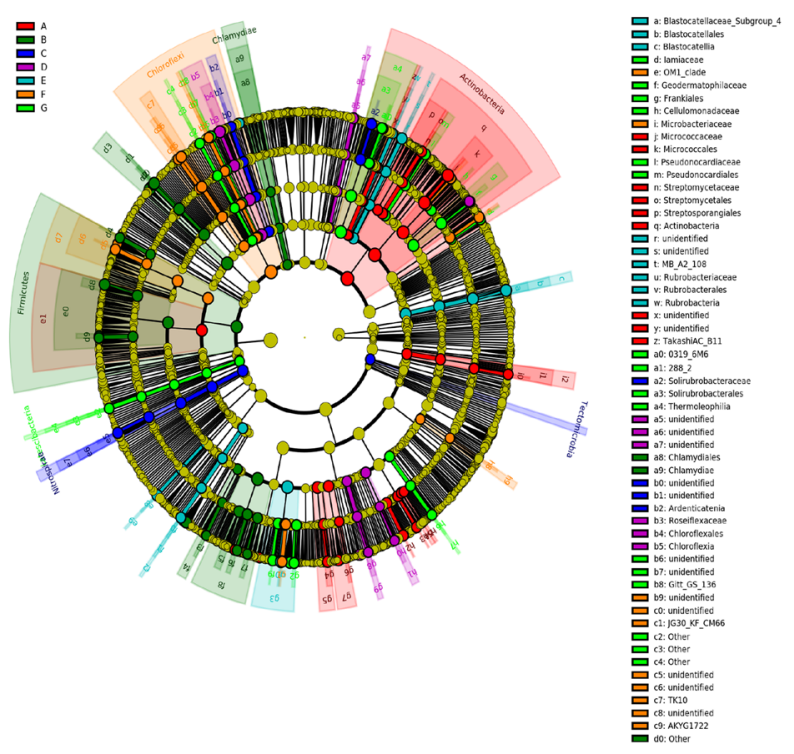

B

Co-occurrence networt

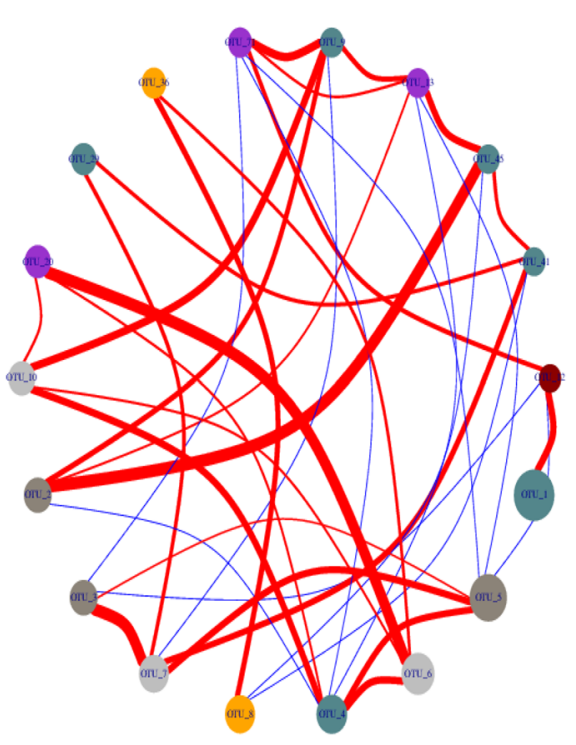

- p_Cyanobacteria

- P_Actinobacteria

- P_Proteobacteria

$\square$ P_Acidobacteria

$\square$ p_Chloroflexi

a P_Thaumarchaeota

Figure 6. (A) The cladogram of soil rhizospheric bacteria generated by LEfSe indicating differences of taxa between treatments. The connection stands for a strong and significant occurelation. The size of each node is proportional to the relative abundance. Red, dark green, blue, purple, grass green, orange, and light green on the bacterial trees indicate the taxa that are enriched in cropping year of 5, 10, 15, 20, 25, 30 and 30 with field corn, respectively $(\mathbf{a}>0.01)$. (B) The co-occurrence network interactions of soil rhizospheric bacteria. The connection stands for a strong and significant ocrrelation. The size of each node is proportional to the relative abundance.

A

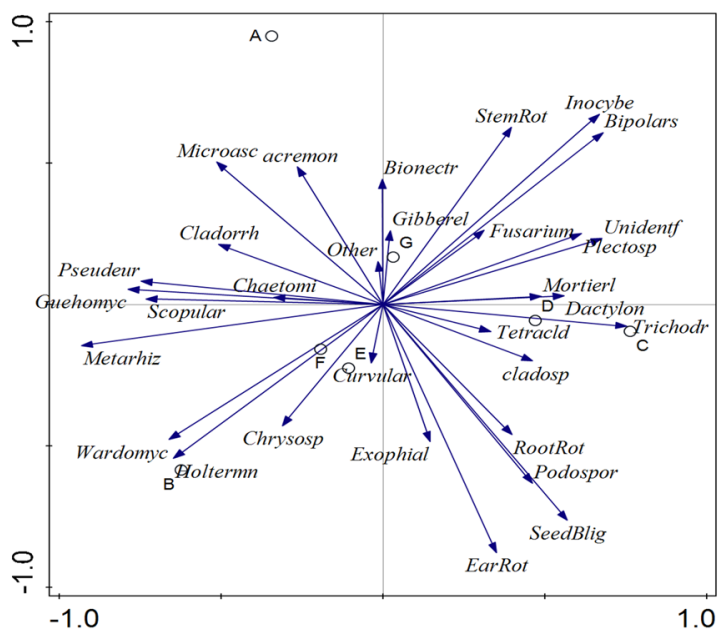

B

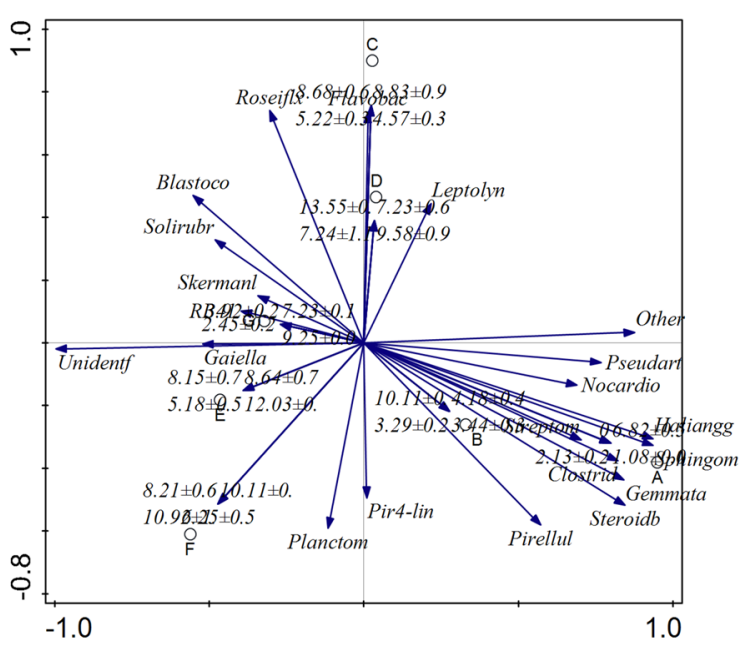

Figure 7. (A) RDA analysis of the relationship between the disease incidence and relative abundance of fungal genus of different cropping years. Correlation between different disease incidence and RDA axes were represent by the length and angel of arrows. (B) RDA analysis of the relationship between the disease incidence of different continuous cropping year and relative abundance of bacteria genus of different cropping years. Correlation between different disease incidence and RDA axes were represent by the length and angel of arrows.

disease control and plant production. PCoA results showed that the samples of the same land use types were often clustered but 30 years cropping with field maize were independent with the other years cropping. RDA analysis also confirmed a closely correlation of plant-microbe between the different disease incidence and microbial community structure and diversity in our study. Our results indicated that optimizing the soil microbial community under factors matric to an appropriate level was urgently needed to keep the plantation healthy. 


\section{Conclusions}

Continuous cropping of maize seed production increased disease incidence with the increase of cropping year, while the highest disease incidence and disease severity of four diseases varied among different cropping years. Mono-maize cropping led to significant difference in the microbial community and diversity among different continuous cropping year. Fungal community diversity increased with the increase of continuous cropping year with exception of 10 years. Ascomycota, Mortierellomycota and Basidiomycota dominated top 3 fungal flora. A certain proportion of pathogenic Fusarium, Gibberella, Cladosporium etc. were detected in the rhizosphere fungi in different continuous cropping year. The relative increase of Fusarium, Gibberella, Cladorrhinum, and the relative decrease of Mortierella, Chrysosporium, Podospora, Chaetomium, and Exophiala with the increase of continuous cropping year potentially contributed to the structural segregation of different cropping year. Proteobacteria, Actinobacteria and Chloroflexi were located in the top 3 among all bacteria phyla. Haliangium and Streptomyces were also found in the soils with a significant decrease with the increase of cropping year. Continuous maize seed production led to the decrease of protective and biocontrol genera, and increased the potential pathogenic pathogen. While relative abundance of potential pathogen varied among different cropping year and led to different disease and incidence. There was a closely correlation between disease incidence and variation of microbial community. Pathogenic disease incidence increased with the increase of cropping year, and the cropping plant is in danger of pathogen invasion. Optimizing the soil microbial community under factors matric to an appropriate level was urgently needed to keep the maize seed production healthy.

\section{Material and methods}

Site description. The study site were located at Shajing town of Zhangye, Gansu province, China, where more than 30 companies with more than hundreds of maize varieties and nearly 3,000 hectares fields were operating for many years. The soil was named as irrigated desert soil with organic matter of $18.56-20.34 \mathrm{~g} \mathrm{~kg}^{-1}$, available-nitrogen of $45-52 \mathrm{mg} \mathrm{kg}$, available-phosphorus of $8.96-12.51 \mathrm{mg} \mathrm{kg}^{-1}$, available-potassium of 164-168 mg kg-1, and $\mathrm{pH}$ of 8.33-8.45. The annual temperature, evaporation, and precipitation were $4{ }^{\circ} \mathrm{C}$, 2000-2100 mm, and 200-243 mm, respectively. Seven site with continuous mono-cropping year of 5 years (A, $\left.39^{\circ} 42^{\prime} 52^{\prime \prime} \mathrm{N}, 100^{\circ} 15^{\prime} 30^{\prime \prime} \mathrm{E}\right), 10$ years (B, 39 $\left.42^{\prime} 52^{\prime \prime} \mathrm{N}, 100^{\circ} 15^{\prime} 30^{\prime \prime} \mathrm{E}\right), 15$ years (C, 39 $\left.5^{\circ} 14^{\prime \prime} \mathrm{N}, 100^{\circ} 15^{\prime} 42^{\prime \prime} \mathrm{E}\right), 20$ years $\left(\mathrm{D}, 39^{\circ} 5^{\prime} 46^{\prime \prime} \mathrm{N}, 100^{\circ} 16^{\prime} 29^{\prime \prime} \mathrm{E}\right), 25$ years $\left(\mathrm{E}, 39^{\circ} 5^{\prime} 17^{\prime \prime} \mathrm{N}, 100^{\circ} 15^{\prime} 40^{\prime \prime} \mathrm{E}\right), 30$ years $\left(\mathrm{F}, 38^{\circ} 59^{\prime} 46^{\prime \prime} \mathrm{N}, 100^{\circ} 20^{\prime} 20^{\prime \prime} \mathrm{E}\right)$ and 30 years $\left(\mathrm{G}, 38^{\circ} 58^{\prime} 35^{\prime \prime} \mathrm{N}, 100^{\circ} 19^{\prime} 53^{\prime \prime} \mathrm{E}\right)$ were selected for our study. Field G has 3 years field maize planting history (Conventional grown, no isolation, the straw is crushed and returned to the field) and all the other fields were under the same fertilization and management mode, and the area of each plot was $36 \mathrm{~m}^{2}(4 \times 9)$ and was separated with the others by isolation.

Soil sample collection. The soil samples of rhizosphere of different mono cropping year were collected after harvest with shaking the soil particles adhering to the maize roots. Each sample was a mixture of rhizosphere soil from 10 plants, and then the root hair, stone and plastic pieces were picked out by hand. Three duplicated samples of the mixture about $5 \mathrm{~g}$ was put into the ice box and transferred to the laboratory at $1 \mathrm{~h}$ for further testing. The samples for high throughput sequence test were preserved at $-20^{\circ} \mathrm{C}$ before posting and posted with dry-ice.

Disease incidence statistics. Incidences of seedling blight, root rot and stem rot were investigated at the seedling stage and the flare opening stage on the basal stem, respectively, while incidence of ear rot was investigated at seedling and adult-plant stage. The diseased plant was washed with running tap water, and assessed for the presence and severity of root rot, stem rot, seedling blight, and ear rot symptoms on a $0-4$ scale according to Zhou et $\mathrm{al}^{46}$, where: 0 means no symptom, 1 means mild symptom, 2 means obvious lesions, 3 means severe lesions on the stem and diminished plant vigor. Disease incidence $(\%)=$ number of infected plants $\times 100 /$ Total number of plants in each block.

DNA extraction, PCR amplification and illumina Miseq sequencing of the soil.

The DNA of samples was extracted by using the MOBIO PowerSoil DNA Isolation $\mathrm{Kit}^{47}$. The genomic DNA was amplified by PCR using the $16 \mathrm{~S}$ rRNA gene V4 region primers (515a-806a). The primers sequence were: GTGCCAGCMGCCGCGGTAA, and GGACTACHVGGGTWTCTAAT. PCR conditions: Denaturation for 5 min at $94{ }^{\circ} \mathrm{C}$, followed by 26 cycles of $30 \mathrm{~s}$ at $94{ }^{\circ} \mathrm{C}, 30 \mathrm{~s}$ at $50{ }^{\circ} \mathrm{C}$, and $60 \mathrm{~s}$ at $72{ }^{\circ} \mathrm{C}$. All reactions ended with a final extension of $7 \mathrm{~min}$ at $72{ }^{\circ} \mathrm{C}$. The amplified product was verified by $1 \%$ agarose gel electrophoresis. The PCR amplification product was further purified by using a purification kit, and the PCR mixed product was recovered by using an EZNA Gel extraction kit (Omega, USA). The illumina Misequence PE 250 (Beijing Allwegene Biotechnology Co. LTD., China) was used for sequencing and microbial community analysis.

Statistical analysis. The sequence data were processed on the quantitative insights into Microbial Ecology platform according to Caporaso et $\mathrm{al}^{48}$. The $97 \%$ similarity of sequence was used as a criterion of the classification of the Operational Taxonomic Units (OTU). The Chao 1 and Shannon diversity were calculated by using the QIIME platform (http://qiime.org/). The open source software Cytoscape $2.8^{49}$ was employed to visualize all the phyla identified based on total read counts. Redundancy analysis (RDA) of the relationship between microbial biomass composition and the disease incidence was carried out by using the CANOCO 5 software. A metagenomic biomarker discovery approach was employed with LEfSe (Linear discriminant analysis) coupled with effect size measurement which performs a nonparametric wilcoxon sum-rank test to assess the effect size of each phylum ${ }^{50}$. The disease incidence were statistically determined with Microsoft Excel and Duncan's multiple range test was applied when the one-way ANOVA showed obvious differences $(p<0.05)$. 
Received: 27 March 2020; Accepted: 24 April 2020

Published online: 15 January 2021

\section{References}

1. Zhao, Y. C., Qin, J. H., Xiao, Z. W. \& Xu, L. Effects of continuous cropping system of maize seed production on soil physicalchemical properties and content of heavy-metal in Hexi corridor. J. Soil Water Conserv. 26, 204-208 (2012).

2. Rahul, K. \& Singh, I. S. Inheritance of resistance to banded leaf and sheath blight (Rhizoctonia solamf. sp. Sasakii) of maize. In Proceedings 8th Asian Regional Maize Works. Bangkok, Thailand 5, 356-365 (2002).

3. Xiao, Z. W., Wang, D. C., Yan, J. Z. \& Cheng, H. Y. Effect of continuous cropping on yield and agronomic and economic traits of maize seed production. Crops 2, 107-109 (2010).

4. Hernández-Rodríguez, A., Heydrich-Pérez, M., Acebo-Guerrero, Y., Velazquez-delValle, M. G. \& Hernández-Lauzardo, A. N. Antagonistic activity of Cuban native rhizobacteria against Fusarium verticillioides (Sacc.) Nirenb in maize (Zea mays L.). Appl. Soil Ecology 39(2), 180-186 (2008).

5. Zhang, Z. L. \& Wang, W. Q. Progress on formation mechanism and control measurements of continuous cropping obstacles in plants. J. Biol. 27, 69-72 (2010).

6. Zhou, X. G. \& Wu, F. Z. Vanillic acid changed cucumber (Cucumis sativus L.) seedling rhizosphere total bacterial, Pseudomonas and Bacillus spp. communities. Sci. Rep. 8, 4929 (2018).

7. Miao, C. P. et al. rhizosphere fungi of Panax notoginseng: diversity and antagonism to host phytopathogens. J. Ginseng Res. 40, 124-134 (2016).

8. Garbeva, P., Veen-Van, J. A. \& Elsas-van, J. D. Microbial diversity in soil: selection microbial populations by plant and soil type and implications for disease suppressiveness. Ann. Rev. Phytopathol. 42, 243-270 (2004).

9. Raaijmakers, J., Paulitz, T., Steinberg, C., Alabouvette, C. \& Moënne-Loccoz, Y. The rhizosphere: a playground and battlefield for soilborn pathogens and beneficial microorganisms. Plant Soil 321(1-2), 341-361 (2009).

10. Mazzola, M. Assessment and management of soil microbial community structure for disease suppression. Annu. Rev. Phytopathol. 42, 35-59 (2004).

11. An, M., Zhou, X., Wu, F. \& Yang, P. Rhizosphere soil microorganism populations and community structures of different watermelon cultivars with differing resistance to Fusarium oxysporum f. sp. Niveum. Canada J. Microb. 57(5), 355-365 (2011).

12. Bonilla, N., Gutierrez-Barranquero, J. A., Vicente, A. \& Cazorla, F. M. Enhancing soil quality and plant health through suppressive organic amendments. Diversity 4(4), 475-491 (2012).

13. Van-Elsas, J. D. et al. Microbial diversity determines the invasion of soil by a bacterial pathogen. Proc. Natl. Acad. Sci. 109, 1159-1164 (2012).

14. Gai, X. T. et al. Infection cycle of maize stalk rot and ear rot caused by Fusarium verticillioides. PLoS ONE 13(7), 14-127 (2018).

15. Miller, S., Shea Reid-Lana, M. \& Harris-Linda, J. Colonization of maize silks by Fusarium Graminearum, the causative organism of Gibberella ear rot. Can. J. Bot. 85, 369 (2007).

16. Shao, P. S. et al. Secondary successional forests undergo tightly coupled changes in soil microbial community structure and soil organic matter. Soil Biol. Biochem. 128, 56-65 (2019).

17. Chinnadurai, C., Gopalaswamy, G. \& Balachandar, D. Diversity of Azotobacter in the semi-arid Alfisol receving long-term organic and inorganic nutrient amendments. Ann. Microb. 63, 1397-1404 (2013).

18. Soman, C., Li, D. F., Wander, M. M. \& Kent, A. D. Long-term fertilizer and crop-rotation treatments differentially affect soil bacterial community structure. Plant soil 413, 145-159 (2016).

19. Zhou, J. et al. Influence of 34-years of fertilization on bacterial communities in an intensively cultivated black soil in northeast China. Soil Biol. Biochem. 90, 42-51 (2015).

20. Treseder, K. K. et al. Evolutionary histories of soil fungi are reflected in their large-scale biogepgraphy. Ecol. Lett. 17, 1086-1093 (2014).

21. Miadlikowska, J. et al. New insights into classification and evolution of the Lecanoromycetes (Pezizomycotina, Ascomycota) from phylogenetic analyses of three ribosomal RNA- and two protein-coding genes. Mycologia 98, 1088-1103 (2006).

22. Lauber, C. L., Strickland, M. S., Bradford, M. A. \& Fierer, N. The influence of soil properties on the structure of bacterial and fungal communities across land-use types. Soil Biol. Biochem. 40, 2407-2415 (2008).

23. Lauber, C. L., Hamady, M., Knight, R. \& Fierer, N. Pyrosequencing-based assessment of soil pH as a predictor of soil bacterial community structure at the continental scale. Appl. Environ. Microbiol. 75, 5111-5120 (2009).

24. Tian, Q. et al. Land-use types and soil chemical properties influence soil microbial communities in the semiarid Loess plateau region in China. Sci. Rep. 7, 45289 (2017).

25. Liu, J. et al. High throughput sequencing analysis of biogeographical distribution of bacterial communities in the black soils of Northeast China. Soil Biol. Biochem. 70, 113-122 (2014).

26. Jeanbille, M. et al. Soil parameters drive the structure, diversity and metabolic potentials of the bacterial communities across temperate beech forest soil sequences. Soil Microbiol. 71, 482-493 (2016).

27. Berg, G. \& Martinez, J. L. Friends or foes: can we make a distinction between beneficial and harmful strains of the Strnotrophomonas Maltophilia complex?. Front Microbiol. 6, 241 (2015).

28. Egamberdieva, D., Jabborova, D. \& Berg, G. Synergistic interactions between Bradyrhizobium japonicum and the endophyte Stenotrophomonas rhizophila and their effects on growth, nodulation of soybean under salt stress. Plant soil 405, 35-45 (2015).

29. Egamberdieva, D., Jabborova, D. \& Hashem, A. Pseudomonas induces salinity tolerance in cotton (Gossypium hirsutum) and resistance to Fusarium root rot through the modulation of indole-3-acetic acid. Saudi J. Biol. Sci. 22(6), 773-779 (2015).

30. Egamberdieva, D., Li, L., Lindström, K. \& Räsãnen, L. A synergistic interaction between salt tolerant Pseudomonas and Mezorhizobium strains improves growth and symbiotic performance of liquorice (Glycyrrhiza uralensis Fish) under salt stress. Appl. Microbiol. Biotechnol. 100(6), 2829-2841 (2016).

31. Fudou, R. et al. Haliangicin, a novel antifungal metabolite produced by a marine myxobacterium. 2. Isolation and structural elucidation. J. Antibiot. 54(2), 153-156 (2001).

32. Shekhar, N., Bhattacharya, D., Kumar, D. \& Gupta, R. K. Biocontrol of wood-rotting fungi with Streptomyces violaceusniger XL-2. Canada J. Microbiol. 52(9), 805-808 (2006).

33. Pieterse, C. M. et al. Induced systemic resistance by beneficial microbes. Ann. Rev. Phytopathol. 52, 347-372 (2014).

34. Schenk, S. T. et al. N-acyl-homoserine lactone primes plants for cell wall reinforcement and induces resistance to bacterial pathogens via the salicylic acid/oxylipin pathway. Plant Cell 26, 2708-2723 (2014).

35. Sieper, T. et al. N-acyl-homoserine lactone uptake and systemic transport in barley rest upon active parts of the plant. New Phytol. 201, 545-555 (2014)

36. Tan, Y. et al. rhizosphere soil and root endogenous fungal diversity and composition in response to continuous Panax notoginseng cropping practices. Microbiol. Res. 194, 10-19 (2017).

37. Tan, Y. et al. Diversity and composition of rhizosphere soil and root endogenous bacteria in Panax notoginseng during continuous cropping practices. J. Basic Microbiol. 57, 337-344 (2017).

38. Berg, G. et al. Lugtenberg BBiocontrol and osmoprotection for plants under salinated conditions. In Molecular Microbial Ecology of the Rhizosphere (eds Frans, J. \& de Bruijn, F. J.) 561-573 (Wiley, Hoboken, 2013). 
39. Abd-Allah, E. F., Hashem, A., Alqarawi, A. A., Bahkali, A. H. \& Alwhibi, M. S. Enhancing growth performance and systemic acquired resistance of medicinal plant Sesbania sesban (L.) Merr using arbusular mycorrhizal fungi under salt stress. Saudi J. Biol. Sci. 22, 274-283 (2015).

40. Miao, Z. Q. et al. The causal microorganisms of Panax notoginseng root rot disease. Sci. Agric. Sin. 39, 1371-1378 (2006).

41. Manamgoda, D. S. et al. The genus bipolaris. Stud. Mycol. 79, 221-228 (2014).

42. Chen, J., Yan, H., Gao, Z., Xue, C. \& Zhuang, J. Identification techniques for physiological differentiation of Curvularia lunata in maize. Acta Phytopathol. Sin. 33, 121-125 (2003).

43. Sturz, A. V. \& Christie, B. R. Beneficial microbial alleopathies in the root zone: the management of soil quality and plant disease with rhizobacteria. Soil Till Res. 72, 107-123 (2013).

44. Alqarawi, A. A., Abd-Allah, E. F. \& Hashem, A. Alleviation of salt-induced adverse impact via mycorrhizal fungi in Ephedra aphylla Forssk. Plant Interact. 9(1), 802-810 (2014).

45. Lambert, R. J. \& White, D. G. Disease reaction changes from tandem selection for multiple disease resistance in two maize synthetics. Crop Sci. 37, 66-69 (1997).

46. Zhou, Q. X., Chen, Y. Y., Yang, Y. L. \& Strelkov, S. E. Effect of inoculum density and quantitative PCR-based detection of Rhizoctonia solani AG-2-1 and Fusarium avenaceum on canola. Crop Protect. 59, 71-77 (2014).

47. Wu, Z. X. et al. Molecular characterization of microbial communities in the rhizosphere soils and roots of diseased and healthy Panax notoginseng. Antonie Van Leeuwenhoek 108(5), 1059-1074 (2015).

48. Caporaso, J. G. et al. QIIME allows analysis of high-throughput community sequencing data. Nat. Methods 7, 335-336 (2010).

49. Shannon, P. et al. Cytoscape: a software environment for integrated models of biomolecular interaction networks. Genome Res. 13, 2498-2504 (2003).

50. Segata, N. et al. Metagenomic biomarker discovery and explanation. Genome Biol. 12, R60 (2011).

\section{Acknowledgements}

This work was supported by the Nature Science Foundation of China (41867010), and the program funds for the Longyuan innovative talents (2050205-1). We greatly thanks for the friendly provision of our study plots of Zhangye Zhongtian Agricultural science and technology Co. LTD.

\section{Author contributions}

Y.Z. and C.H. wrote the main manuscript text. G.C. and H.C. prepared Tables 1 and 2. W.F., Z.W. and Y.C. prepared all the figures. Z.X. reviewed the manuscript.

\section{Competing interests}

The authors declare no competing interests.

\section{Additional information}

Correspondence and requests for materials should be addressed to Y.Z. or C.H.

Reprints and permissions information is available at www.nature.com/reprints.

Publisher's note Springer Nature remains neutral with regard to jurisdictional claims in published maps and institutional affiliations.

(c) (i) Open Access This article is licensed under a Creative Commons Attribution 4.0 International License, which permits use, sharing, adaptation, distribution and reproduction in any medium or format, as long as you give appropriate credit to the original author(s) and the source, provide a link to the Creative Commons licence, and indicate if changes were made. The images or other third party material in this article are included in the article's Creative Commons licence, unless indicated otherwise in a credit line to the material. If material is not included in the article's Creative Commons licence and your intended use is not permitted by statutory regulation or exceeds the permitted use, you will need to obtain permission directly from the copyright holder. To view a copy of this licence, visit http://creativecommons.org/licenses/by/4.0/.

(C) The Author(s) 2021 